\title{
Role of stem cell growth factor/c-Kit in the pathogenesis of irritable bowel syndrome (Review)
}

\author{
YUNA CHAI $^{1,2^{*}}$, YUSHENG HUANG $^{2 *}$, HONGMEI TANG $^{3}$, XING TU $^{4}$, JIANBO HE $^{5}$, \\ TING WANG ${ }^{2}$, QINGYE ZHANG ${ }^{3}$, FEN XIONG $^{3},{\text { DETANG } \text { LI }^{3} \text { and ZHENWEN QIU }}^{3}$
}

\author{
${ }^{1}$ Pharmaceutical Department, First Affiliated Hospital of Zhengzhou University of Chinese Medicine, Zhengzhou, \\ Henan 450052; ${ }^{2}$ Chinese Medicine Program, The First Clinical School of Guangzhou University of Chinese Medicine; \\ ${ }^{3}$ Pharmaceutical Department, First Affiliated Hospital of Guangzhou University of Chinese Medicine, Guangzhou, \\ Guangdong 510405; ${ }^{4}$ Institute of Traditional Chinese Medicine, School of Traditional Chinese Medicine of \\ Hubei University for Nationalities, Enshi, Hubei $445000 ;{ }^{5}$ Department of Orthopedics, The Second Clinical \\ School of Guangzhou University of Chinese Medicine, Guangzhou, Guangdong 510405, P.R. China
}

Received November 26, 2015; Accepted November 25, 2016

DOI: $10.3892 / \mathrm{etm} .2017 .4133$

\begin{abstract}
Irritable bowel syndrome (IBS) is a functional bowel disease with a complicated etiopathogenesis, often characterized by gastrointestinal motility disorder and high visceral sensitivity. IBS is a comprehensive multi-systemic disorder, with the interaction of multiple factors, such as mental stress, intestinal function and flora, heredity, resulting in the disease. The existence of a common mechanism underlying the aforementioned factors is currently unknown. The lack of therapies that comprehensively address the disease symptoms, including abdominal pain and diarrhea, is a limitation of current IBS management. The current review has explored the role of the SCF/c-Kit receptor/ligand system in IBS. The $\mathrm{SCF} / \mathrm{c}-\mathrm{Kit}$ system constitutes a classical ligand/receptor tyrosine kinase signaling system that mediates inflammation and
\end{abstract}

Correspondence to: Professor Hongmei Tang, Pharmaceutical Department, First Affiliated Hospital of Guangzhou University of Chinese Medicine, 12 Ji Chang Road, Guangzhou, Guangdong 510405, P.R. China

E-mail: tanghongmei2000@163.com

${ }^{*}$ Contributed equally

Abbreviations: IBS, irritable bowel syndrome; SCF, stem cell factor; ICC, intestinal cells of Cajal; RTK, receptor tyrosine kinase; GI, gastrointestinal; SMC, smooth muscle cell; Src, a tyrosine-protein kinase; SP, substance P; NK1, neurokinin-1; TRPV, transient receptor potential vanilloid; 5-HT, 5-hydroxytryptamine; MC, mast cell; NC, nerve cell; NS, nervous system; ENS, enteric nervous system; ANS, autonomic nervous system; CNS, central nervous system; NF- $\kappa \mathrm{B}$, nuclear factor- $\kappa \mathrm{B}$; TNF- $\alpha$, tumor necrosis factor- $\alpha$

Key words: irritable bowel syndrome, gastrointestinal motility, stem cell factor (SCF)/c-Kit, ligand/receptor tyrosine kinase signaling system, inflammation, neuromodulation smooth muscle contraction. Additionally, it provides trophic support to neural crest-derived cell types, including the enteric nervous system and mast cells. The regulation of SCF/c-Kit on the interstitial cells of Cajal (ICC) suggest that it may play a key role in the aberrant intestinal dynamics and high visceral sensitivity observed in IBS. The role of the SCF/c-Kit system in intestinal motility, inflammation and nerve growth has been reported. From the available biomedical evidence on the pathogenesis of IBS, it has been concluded that the SCF-c-Kit system is a potential therapeutic target for rational drug design in the treatment of IBS.

\section{Contents}

1. Introduction

2. Biological functions of the $\mathrm{SCF} / \mathrm{c}-\mathrm{Kit}$ system

3. Regulation of the SCF/c-Kit system affects the function of a variety of cells

4. Relationship between the SCF/c-Kit axis and neuroendocrine immune regulation in IBS

5. $\mathrm{SCF} / \mathrm{c}-\mathrm{Kit}$ and visceral hypersensitivity in IBS

6. Conclusion

\section{Introduction}

Irritable bowel syndrome (IBS) is one of the most prevalent chronic and functional bowel diseases, resulting in considerable misery across the globe (1-3). The disease is characterized by substantial abdominal pain and discomfort; however, it lacks anatomical or histological aberrations or consistent changes in clinical chemistry $(4,5)$. The current incidence of IBS is between $7-21 \%$ worldwide, a phenomenon attributed to an increased pace of life and alterations in diet (6). Identified risk factors requiring further investigation include psychological stress, changes in social environment, noxious gut stimuli and specific dietary factors. Experimental and 
emerging treatments, including fecal transplantation, have also been linked to IBS pathogenesis (7), further demonstrating the need for more detailed study into the IBS risk factors. Greater understanding of factors associated with the disease is potentially critical for future improvements in disease prevention and therapy.

The obscurity of IBS pathogenesis is a hindrance to such progress, though it is generally accepted that high visceral sensitivity and disturbed gut motility, in combination with low-grade inflammation, cause IBS via neuroendocrine and immune dysfunction (8). However, identifying the factors that mediate this dysfunction is still a major challenge in current IBS research. Clues into the etiology of the disease may be provided by study into the neurotransmitter dynamics of the brain-gut axis and associated endocrinological factors $(9,10)$, as well as the intestinal flora, though a single factor alone cannot explain the complexity of IBS pathogenesis. Nevertheless, research should provide important insights into pathomechanism of IBS that potentially lead to novel drug development for the treatment of IBS.

The available evidence suggests that stem cell factor (SCF) expression is increased in clinical IBS (11). The system composed of SCF and its cognate receptor, c-Kit, is a principal regulator of survival and functionality for a multitude of neural crest-derived cell types, in particular for those involved in visceral perception, smooth muscle contraction and inflammation (12-14). Disorders of the neuro-endocrine-immunological network resulting from alterations in the SCF/c-Kit system provide an explanation for the high visceral sensitivity, abnormal bowel contraction strength and low-grade inflammation experienced in IBS, suggesting that this system may be an important target for intervention $(15,16)$. In the present review, the current trends in IBS are investigated, highlighting the regulation of $\mathrm{SCF} / \mathrm{c}-\mathrm{Kit}$.

\section{Biological functions of the SCF/c-Kit system}

The c-Kit receptor is the product of the $c$-kit proto-oncogene and belongs to the receptor tyrosine kinase (RTK) superfamily, with the members of this family being the cardinal regulators of cellular fate in the mammalian body (17). As an important member of the type III RTK family, it has a highly specific and restricted expression pattern, with prominent $\mathrm{c}-\mathrm{Kit}$ levels expressed on the surface of hematopoietic cells, mast cells (MCs) and interstitial cells of Cajal (ICC) $(18,19)$. The cognate ligand of c-Kit is SCF, alternatively known as dry factor or $\mathrm{MC}$ growth factor, which is synthesized in abundance by the gastrointestinal (GI) tract smooth muscle cells (SMCs) (20). The expression patterns of SCF and c-Kit are thus consistent with their potential involvement in IBS.

In the $\mathrm{SCF} / \mathrm{c}-\mathrm{Kit}$ mechanism, as presented in Fig. 1, extracellular SCF binds specifically with c-Kit, with few alternate receptors proposed. Following SCF binding, c-Kit homodimers are formed via activation of the enzymatic kinase domain within the receptor (21). This provokes autophosphorylation of tyrosine residues within the receptor's cytoplasmic C-termini. The phosphotyrosine residues serve as docking sites for receptor adaptor proteins, in turn provoking activation of a range of signal transduction pathways (22). These can involve the following signaling molecules: Phosphatidylinositol 3-kinase (PI3K), single-subunit small GTPases/extracellular regulated protein kinases (Ras/Erk), janus kinase/signal transducers and activators of transcription (JAK/STAT), phospholipase C (PLC) $-\gamma$ and the tyrosine-protein kinase Src $(16,22)$. Specific expression of genes typically results and a range of biological signals are initiated to regulate the survival, proliferation, differentiation, apoptosis, motility and migration of c-Kit bearing cells (22).

\section{Regulation of the SCF/c-Kit system affects the function of a variety of cells}

Cell lines regulated by the SCF/c-Kit system prominently include ICC, other enteric nerve cells (NCs) and MCs. In general, SCF is a trophic factor for neural crest derivatives, with similar effects on ICC in terms of differentiation and proliferation (23). SCF specifically increases expression of the key gap junction protein connexin 43 (Cx43), resulting in improved network function by promoting intercellular conduction of electric stimuli (24). Furthermore, SCF promotes MC hyperplasia and enhances the release of MC-derived pro-inflammatory mediators (25-27). The main mediators released are histamine, serotonin and arachidonic acid-derived compounds (leukotrienes, prostaglandins (28), interleukin), which in turn reduce the integrity of the local microcirculation and elicit an inflammatory response of body (29-31). Additionally, SCF increases the intrinsic pacemaker rhythm of ICC that regulates GI smooth muscle contraction, via phosphorylation of substance P (SP), neurokinin-1 (NK1), transient receptor potential vanilloid-1 (TRPV1) receptors and by promoting the conduction of pain signals towards the central nervous system (CNS) (32). When considering the consequences of alterations in these biological signals, a potential role of the $\mathrm{SCF} / \mathrm{c}-\mathrm{Kit}$ axis in IBS pathophysiology emerges. It can be argued that this axis contributes to the high visceral sensitivity, exaggerated contraction and inflammation observed in IBS, thus explaining how stress and psychological factors are related to abdominal pain and discomfort in IBS.

In this context, it is noteworthy that structural loss in the ICC is a potential factor in IBS pathogenesis $(15,33)$. ICCs constitute an elaborate network of contraction-controlling cells, present in all muscle layers of the GI tract and other internal structures, including the stomach, small intestine, pancreas, colon and bladder, where they regulate a range of biological functions. Based on their morphology, distribution and anatomical relationship with nerve plexus and smooth muscle, ICC are categorized into four subtypes (34): i) Myenteric ICC (IC-MY), located between circular and longitudinal muscle layers of the stomach, small intestine, colon and other muscles (35); ii) submucosal ICC (IC-SM), distributed along the submucosal layer of the surficial colon circular beam (36); iii) deep muscular ICC, (IC-DMP), located between the inner thin layer and outer thick layer of the intramuscular ring, particularly in the small intestine (37); and iv) intramuscular ICC, (IC-IM), located in all areas of the muscle layers above (35). MY and IC-SM serve mainly as GI pacemakers. IC-DMP and IC-IM are typically associated with the transmission of enteric nerve signals. The ICC types constitute an intricate network, fundamental to GI electrophysiological activity (22). Importantly, cross-talk with the 
CNS exists and the ICC stimulate the sensory nerve of the GI tract through direct synaptic contact (38-40). The ICC are key to gastroenterological function and, conversely, the SCF/c-Kit axis is important for the development and phenotypic differentiation of the ICC, as well as ICC membrane polarization and pacemaker activity. Thus, a defining role of the axis in transcriptional regulation effecting intestinal bowel movement and intestinal rhythm is possible (41). Indeed, in experimental rodents, neutralizing antibody targeting c-Kit resulted in major loss of ICC from the jejunum, whereas high-dose SCF reversed this effect (23). Together with the cardinal functionality of ICC in visceral motility (including pacemaker activity, regulation of peristaltic bowel movement and other aspects of smooth muscle cell functionality), these results indicate that key aspects of GI physiology require functional SCF/c-Kit signaling. Though it is noteworthy that the SCF/c-Kit axis controls mainly long-term changes in ICC physiology, where it is directly controlled by receptors for NK1, NO, 5-hydroxytryptamine (5-HT) and SP, expressed on the ICC surface.

Other cell types controlled by the SCF/c-Kit axis include MCs, a specific type of immune cell required for barrier protection in the intestinal mucosa. An important event in IBS pathogenesis is MC degranulation (42), whereby MC release 5-HT, histamine, TNF- $\alpha$ and various interleukins, all of which are known to aggravate intestinal inflammation and affect visceral perception (43). The development and migration of MCs depend on SCF. For instance, SCF promotes the adhesion and proliferation of MCs by regulating expression of intercellular adhesion molecule-1 (44). As a chemotactic factor of MCs, SCF may promote the regeneration of MC from $\mathrm{CD}_{34}{ }^{+}$progenitor cells, MC survival and adhesion to the extracellular matrix (25). Importantly, histamine levels decline substantially when the SCF/c-Kit system is repressed and the $\mathrm{SCF} / \mathrm{c}-\mathrm{Kit}$ axis has been repeatedly identified as one of the most promising targets for controlling MC inflammation $(26,45)$. Indeed, evidence suggests that SCF inhibition potentially lowers visceral sensitivity via modulation of the MC compartment (46).

Additionally, control of neuronal electrical activity is key to reducing excessive intestinal motility in IBS. The signaling pathway provoked by $\mathrm{SCF} / \mathrm{c}-\mathrm{Kit}$ activity maintains survival, proliferation and nutrition of the neural crest cells, as well as inducing their differentiation and migration (47). c-Kit expression is a typical characteristic of post-mitotic nerve cells in the early stages of lineage differentiation from neurons to glial cells. SCF stimulates nerve regeneration both in experimental rodents and in vitro (48). Although indirect, these associations point to a central role of the SCF/c-Kit axis in organizing neural networks and represent targets for IBS treatment.

ICC, MC and NC are not independent structures and undergo interactions when IBS occurs throughout the nervous system (NS), digestive system, immune system and other regions (49-52). They constitute a large and intricate network system, potentially of critical importance in IBS due to its control of a range of intestinal functions, including visceral sensitivity and inflammatory responses. However, it is also important to note that the ICC, MCs and NCs are not the sole targets of SCF/c-Kit activity, with other cell targets of $\mathrm{SCF} / \mathrm{c}-\mathrm{K}$ it having potential involvement in IBS.

\section{Relationship between the SCF/c-Kit axis and neuroendocrine-immune regulation in IBS}

SCF/c-Kit and neurological disorders. Neurological disorders, including those of the enteric nervous system (ENS), the autonomic nervous system (ANS) and the CNS, contribute to visceral hypersensitivity and GI motility disorder in IBS (53). Upon stimulation by intestinal irritation and/or psychological or emotional factors, the three strands of the NS integrate the stimulus information to generate a GI effector response and cause pain sensation. Appropriate execution of this process depends on the structural integrity and electrophysiological properties of the intestinal neurons involved, which are in turn controlled by the SCF/c-Kit axis: SCF is constitutively expressed in various regions of the NS including the CNS, ENS and ANS, but specific expression levels are influenced by external stimuli (54). SCF directly affects neurotransmission by binding its receptor c-Kit and this influences the efficacy of the NS response to external stimuli (12). Indeed, experimental studies in a depression mouse model revealed a correlation between decreased c-Kit expression in the hippocampus and impaired neuronal differentiation and migration (55). It is well established that severe depression is a key factor predisposing to IBS development $(56,57)$. Therefore, a relationship between altered SCF/c-Kit signals with the emotional, psychological and physical stimulated state of IBS patients is possible (58). Potential effector mechanisms may depend on $\mathrm{SCF} / \mathrm{c}-\mathrm{Kit}$-mediated effects on the phosphorylation status of receptor systems involved in sensing neurotransmitter levels, including the neuronal nitric oxide synthase (nNOS), SP, NK1 and TRPV1 systems $(59,60)$. This has been shown to result in overstimulation of the nerve-ICC-smooth muscle signal transfer system, promoting development of IBS-like symptoms (61). Similarly, in experimental IBS, changes in the regulation of SCF/c-Kit may stimulate strong nerve reflexes and enhance the rhythm of smooth muscle contraction, while simultaneously stimulating pain perception $(14,62)$. However, the contributions of such activity to clinical IBS remains to be established.

SCF/c-Kit axis and abnormalities of the endocrine system. It is well established that malfunction of the brain-gut axis is a key mechanism in explaining IBS pathogenesis (63). In addition to direct innervation between the brain and the gut, it is often assumed that the endocrine system is an important connection between the two systems. Indeed, there is an established link between disturbed serum hormone levels and IBS $(60,64)$, due to hormone secretion typically being related to the psychological state of the patient. This may explain IBS-related stress and other psychological disorders. Relevant mediators include 5-HT, nerve peptide Y, calcitonin gene-related peptide and histamine $(65,66)$. The secretion of these is altered by the patient's psychological state, with the secreted factors targeting the intestinal ICC network. The SCF/c-Kit axis may facilitate the perception of such endocrinological signals, as it has been found that stimulation of c-Kit provokes substantial leukotriene $\mathrm{C} 4$ release via the activation of cytosolic phospholipase A2 (67). This is then associated with increased affinity of histamine and 5HT receptors for their ligands $(68,69)$. As such, the SCF/c-Kit axis promotes sensitivity to GI hormones 


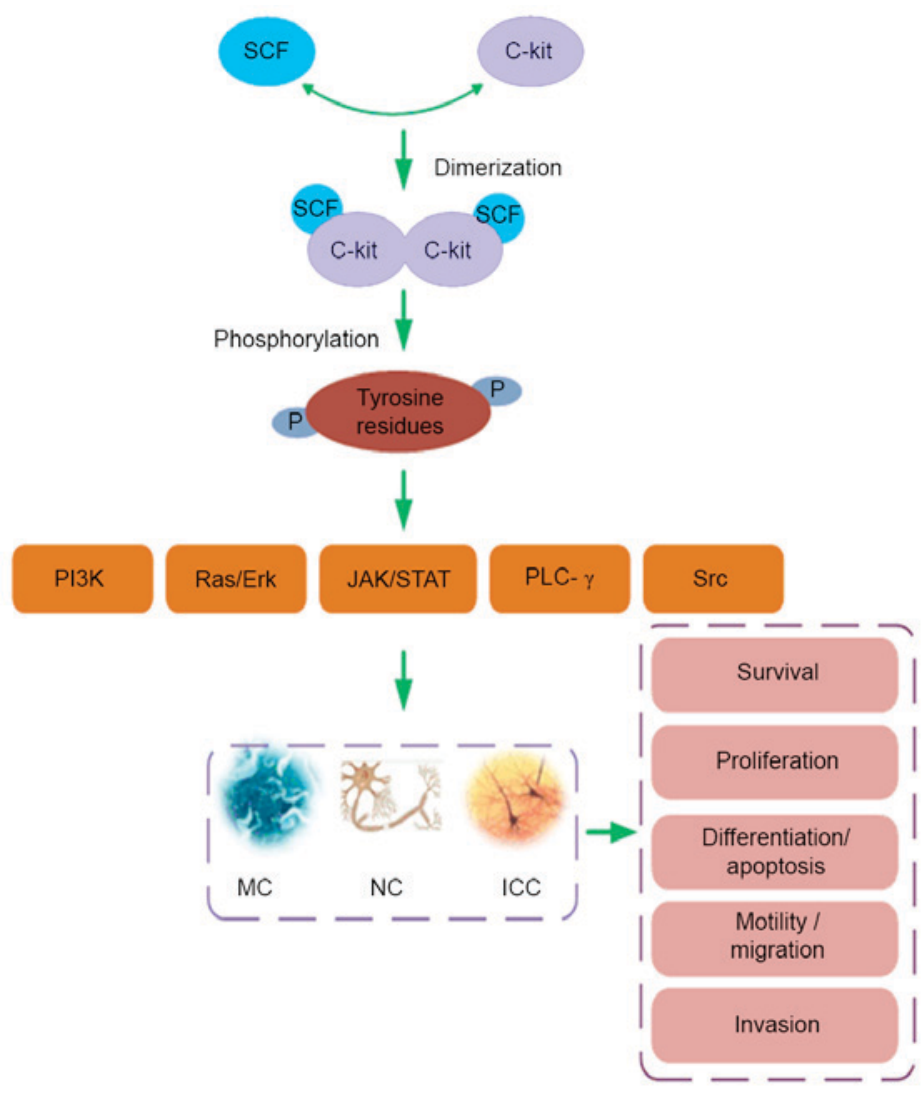

Figure 1. The SCF/c-Kit ligand/receptor system affects the biological function of MCs, NCs and ICC. Dimerization of c-Kit after engagement of SCF with the receptor induces phosphorylation of tyrosine residues in the receptor's cytoplasmic tail. The phosphotyrosines serve as docking sites for adaptor proteins which mediate further signal transduction, leading to activation of the following pathways: PI3K, Ras/Erk, JAK/STAT, PLC- $\gamma$ and Src. In turn these pathways regulate the survival, proliferation, differentiation, apoptosis, motility, migration and invasion of MCs, NCs and the ICC. Stem cell factor (SCF)/c-Kit, ligand/receptor tyrosine kinase signaling system; MC, mast cell; NC, nerve cell, ICC, intestinal cells of Cajal; SCF, stem cell factor; PI3K, phosphatidylinositol 3-kinase; Ras, a guanosine-nucleotide-binding protein (G protein); Erk, extracellular regulated protein kinases, JAK, janus kinase; STAT, signal transducer and activator of transcription; PLC- $\gamma$, phospholipase C- $\gamma$; Src, a tyrosine-protein kinase.

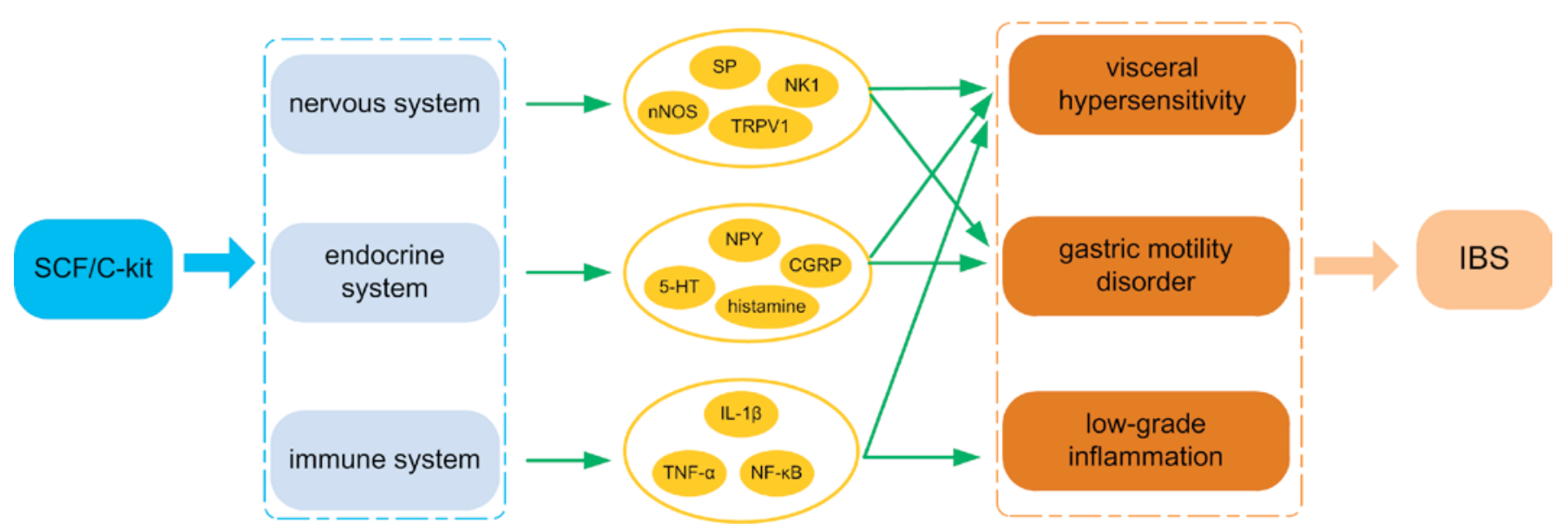

Figure 2. The SCF/c-Kit system affects visceral hypersensitivity, the course of gastric motility disorder and the low-grade inflammation associated with these through the enteric neuro-endocrine-immunological system triggering advanced IBS. Stem cell factor (SCF)/c-Kit, ligand/receptor tyrosine kinase signaling system; IBS, irritable bowel syndrome.

and thus may have a detrimental influence on pain perception, inflammation and bowel movement.

SCF/c-Kitand the immune system.Low-grade intestinal inflammation is established as a key characteristic of IBS $(70,71)$ and is related to MC activation, as well as altered permeability of the intestinal mucosa to antigens $(71,72)$. The general principal genomic regulator of the inflammatory response is nuclear factor- $\kappa \mathrm{B}(\mathrm{NF}-\kappa \mathrm{B})$. Inactive NF- $\kappa \mathrm{B}$ is sequestered in the cytoplasm, while activated NF- $\kappa B$ enters the nucleus and stimulates transcription of a range of proinflammatory factors, including tumor necrosis factor- $\alpha$ (TNF- $\alpha$ ) and interleukin- $1 \beta$. 
C-kit may activate NF- $\kappa \mathrm{B}$ and promote the release of TNF- $\alpha$ when it is sensitized, which may be one way of SCF/C-kit initiating the immune inflammatory response $(51,73)$. In addition, the trophic action of SCF/c-Kit on the MC compartment is directly associated with diarrhea-predominant IBS. Furthermore, c-Kit-mediated cysteinyl production results in sensitization of $\mathrm{MC}$ receptors involved in secretion of proinflammatory mediators, in turn enhancing the inflammatory response. These findings demonstrate a mild inflammatory response is stimulated through $\mathrm{SCF} / \mathrm{c}-\mathrm{Kit}$ signaling, which potentially links to IBS pathogenesis.

\section{SCF/c-Kit and visceral hypersensitivity in IBS}

Zhang et al developed an IBS rat model via infection with Trichinella spiralis (74). Rat models are generally not appropriate targets for genetic intervention, however, imatinib mesylate (STI-571), a moderately specific blocker of c-Kit (75), is amenable to experimental investigation in this model. A previous study revealed that the change of intestinal ICC activator rectus muscle electricity and dorsal commissural nucleus (DCN) were higher in the IBS rat, compared with the other rat model, whereas they decreased significantly following STI-571 exposure. It was indicated that visceral hypersensitivity in IBS rats may be suppressed when blocked the SCF/C-kit signal (74). These results indicate the importance of the SCF/c-Kit axis in IBS and the pharmacological implications of this axis, with imatinib offering a potential therapeutic option for targeting visceral hypersensitivity.

Visceral hypersensitivity is a key characteristic of IBS. The strong dependence of IBS-related pain on psychological and environmental conditions indicates that the pain is under CNS control, however, activity and sensitivity of the spinal sensory nerve fibers may additionally be dependent on endocrinological control $(9,10)$. In this instance, the neurotrophic action of SCF may directly affect and stimulate neurotransmitter responses via the SCF-c-Kit axis (12). In the ENS, periodic slow wave potentials between the ICC and SMCs are generated and perceived by neurotransmitter receptors, including those for SP, vasoactive intestinal peptide, histamine, serotonin and acetylcholine, expressed on the ICC membranes. In turn, these receptors mediate contractile and relaxant effects in GI smooth muscle and pain perception (76). As stated above, MCs may further amplify the pain signals (77), though the pain threshold itself appears largely dependent on the activation state of the SCF/c-Kit axis. Small intestinal resection and transmission microscopy observations indicate that modifying the c-Kit pathway or activating the SCF/c-Kit pathway affects the depolarization and pacemaker functions of the ICC and alters intestinal rhythm (78). However, whether clinical trials employing imatinib provide benefit for these effects is unclear and warrants further study.

\section{Conclusion}

IBS is a functional disease associated with multiple systems in the body, though it is particularly associated with brain-gut cross-talk via modulation of the endocrine system. The results of this include aberrant GI motility and visceral hypersensitivity, in turn leading to abdominal discomfort and abnormal defecation patterns. The $\mathrm{SCF} / \mathrm{c}-\mathrm{Kit}$ signaling system is critical in controlling many of the elements involved (Fig. 2), including ICC MC and nerve cells, and thus shows potential as a pharmacological, intervention aimed at combatting visceral sensitivity and GI disorder in IBS patients. The ICC serve as the pacemakers for GI smooth muscle contraction and integrate neuroendocrine physiology (72). ICCs depend on $\mathrm{SCF} / \mathrm{c}-\mathrm{Kit}$ interaction for growth and development and respond to its signaling by upregulating neurotransmission. Pain perception in ICCs is increased through the effects of $\mathrm{SCF} / \mathrm{c}-\mathrm{Kit}$ on MCs. Fortunately, pharmacological antagonists for SFC/c-Kit signaling are clinically available. For instance, inhibitors including imatinib, sorafenib, lapatinib and sunitinib are capable at a minimum of partially targeting this signaling system (73-75). In addition, imatinib is reasonably c-Kit-specific, however the physiological importance of $\mathrm{SCF} / \mathrm{c}-\mathrm{Kit}$ signal transduction in nearly all cell types derived from the neuronal crest lineage may prevent the use of inhibitory strategies. As a factor involved in GI motility, visceral sensitivity and inflammatory signaling, blockade of SCF/c-Kit may trigger collateral damage, which would likely preclude its use in a non-lethal disease such as IBS $(76,77)$. Therefore, further studies with animal models are required to develop acceptable interventions. In addition, further insight is required into the mechanisms mediating $\mathrm{SCF} / \mathrm{c}-\mathrm{Kit}$ signaling. Design of new drugs specifically inhibiting SCF/c-Kit signal transduction, that preferentially act locally in the intestine, may be critical for successful outcomes. Such targeting of $\mathrm{SCF} / \mathrm{c}-\mathrm{Kit}$ inhibition is a novel strategy in IBS therapy.

\section{Acknowledgements}

This study was supported by the Guangdong province Nature Science Foundation of China (grant no. 2014A030313404), the Natural Science Foundation of China (grant no. 81673842) and the 'Excellent Doctoral Dissertation Incubation Grant' from the First Clinical School of Guangzhou University of Chinese Medicine (grant no. YB201402).

\section{References}

1. Chassany O, Bonaz B, Bruley DES Varannes S, Bueno L,Cargill G, Coffin B, Ducrotté P and Grangé V: Acute exacerbation of pain in irritable bowel syndrome: Efficacy of phloroglucinol/trimethylphloroglucinol. A randomized, double-blind, placebo-controlled study. Aliment Pharmacol Ther 25: 1115-1123, 2007.

2. Horwitz BJ and Fisher RS: The irritable bowel syndrome. N Engl J Med 344: 1846-1850, 2001

3. Moghimi-Dehkordi B, Vahedi M, Pourhoseingholi MA, Khoshkrood Mansoori B, Safaee A,Habibi M, Pourhoseingholi A and Zali MR: Economic burden attributable to functional bowel disorders in Iran: A cross-sectional population-based study. J Dig Dis 12: 384-392, 2011.

4. Schonrich S, Brockow T, Franke T, Dembski R, Resch KL and Cieza A: Analyzing the content of outcome measures in clinical trials on irritable bowel syndrome using the international classification of functioning, disability and health as a reference. Rehabilitation (Stuttg) 45: 172-180, 2006.

5. Spinelli A: Irritable bowel syndrome. Clin Drug Investig 27: 15-33, 2007.

6. Chey WD, Kurlander J and Eswaran S: Irritable bowel syndrome: A clinical review. JAMA 313: 949-958, 2015.

7. Konstantinov SR and Peppelenbosch MP: Fecal microbiota transfer may increase irritable bowel syndrome and inflammatory bowel diseases-associated bacteria. Gastroenterology 144: e19-e20, 2013. 
8. Saha L: Irritable bowel syndrome: Pathogenesis, diagnosis, treatment, and evidence-based medicine. World J Gastroenterol 20: 6759-6773, 2014.

9. Bajwa SJ and Haldar R: Endocrinological disorders affecting neurosurgical patients: An intensivists perspective. Indian J Endocrinol Metab 18: 778-783, 2014.

10. Baldinger P, Kranz G, Höflich A, Savli M, Stein P, Lanzenberger R and Kasper S: The effects of hormone replacement therapy on mind and brain. Nervenarzt 84: 14-19, 2013 (in German).

11. Yang J, Shi YQ and Zhao XY: Expression and significance of $\mathrm{SCF}$ and 5-HT in the intestinal mucosa of patients with diarrhea predominant irritable bowel syndrome. Jilin Medicine 4: 646-647, 2015

12. Sun YG, Gracias NG, Drobish JK, Vasko MR, Gereau RW and Chen ZF: The c-kit signaling pathway is involved in the development of persistent pain. Pain 144: 178-186, 2009.

13. Jin QH, Shen HX, Wang H, Shou QY and Liu Q: Curcumin improves expression of $\mathrm{SCF} / \mathrm{c}$-kit through attenuating oxidative stress and NF- $\kappa$ B activation in gastric tissues of diabetic gastroparesis rats. Diabetol Metab Syndr 5: 12, 2013.

14. Liu G, Chen ZY, Ma L, Lou X, Li SJ and Wang YL: Intracranial hemangiopericytoma: MR imaging findings and diagnostic usefulness of minimum ADC values. J Magn Reson Imaging 38 : $1146-1151,2013$

15. Eshraghian A and Eshraghian H: Interstitial cells of Cajal: A novel hypothesis for the pathophysiology of irritable bowe syndrome. Can J Gastroenterol 25: 277-279, 2011.

16. Zhou YL, Zhang W, Gao EL, Dai XX, Yang H, Zhang XH and Wang OC: Preoperative BRAF mutation is predictive of occult contralateral carcinoma in patients with unilateral papillary thyroid microcarcinoma. Asian Pac J Cancer Prev 13: 1267-1272, 2012.

17. Feng ZC, Riopel M, Popell A and Wang R: A survival Kit for pancreatic beta cells: Stem cell factor and c-Kit receptor tyrosine kinase. Diabetologia 58: 654-665, 2015.

18. Edling CE and Hallberg B: c-Kit-a hematopoietic cell essential receptor tyrosine kinase. Int J Biochem Cell Biol 39: 1995-1998, 2007.

19. Tamada $\mathrm{H}$ and Kiyama $\mathrm{H}$ : Existence of c-Kit negative cells with ultrastructural features of interstitial cells of Cajal in the subserosal layer of the W/Wv mutant mouse colon. J Smooth Muscle Res 51: 1-9, 2015.

20. Morimoto M: Intestinal smooth muscle cells locally enhance stem cell factor (SCF) production against gastrointestinal nematode infections. J Vet Med Sci 73: 805-807, 2011.

21. Ali S and Ali S: Role of c-kit/SCF in cause and treatment of gastrointestinal stromal tumors (GIST). Gene 401: 38-45, 2007.

22. Liang J, Wu YL, Chen BJ, Zhang W, Tanaka Y and Sugiyama H: The C-kit receptor-mediated signal transduction and tumor-related diseases. Int J Biol Sci 9: 435-443, 2013.

23. Tong W, Jia H, Zhang L, Li C, Ridolfi TJ and Liu B: Exogenous stem cell factor improves interstitial cells of Cajal restoration after blockade of c-kit signaling pathway. Scand J Gastroenterol 45 : 844-851, 2010

24. Tan YY, Ji ZL, Zhao G, Jiang JR, Wang D and Wang JM: Decreased SCF/c-kit signaling pathway contributes to loss of interstitial cells of Cajal in gallstone disease. Int J Clin Exp Med 7: 4099-4106, 2014

25. Das Roy L, Curry JM, Sahraei M, Besmer DM, Kidiyoor A, Gruber HE and Mukherjee P: Arthritis augments breast cancer metastasis: Role of mast cells and SCF/c-Kit signaling. Breast Cancer Res 15: R32, 2013.

26. Reber L, Da Silva CA and Frossard N: Stem cell factor and its receptor c-Kit as targets for inflammatory diseases. Eur J Pharmacol 533: 327-340, 2006.

27. Okayama Y and Kawakami T: Development, migration, and survival of mast cells. Immunol Res 34: 97-115, 2006.

28. Bos CL, Richel DJ, Ritsema T, Peppelenbosch MP and Versteeg HH: Prostanoids and prostanoid receptors in signal transduction. Int J Biochem Cell Biol 36: 1187-1205, 2004.

29. Movat HZ: The role of histamine and other mediators in microvascular changes in acute inflammation. Can J Physiol Pharmacol 65: 451-457, 1987

30. Magierowski M, Jasnos K, Kwiecien S, Drozdowicz D, Surmiak M, Strzalka M, Ptak-Belowska A, Wallace JL and Brzozowski T: Endogenous prostaglandins and afferent sensory nerves in gastroprotective effect of hydrogen sulfide against stress-induced gastric lesions. PLoS One 10: e0118972, 2015
31. Di Gennaro A and Haeggström JZ: The leukotrienes: Immune-modulating lipid mediators of disease. Adv Immunol 116: 51-92, 2012.

32. Huizinga JD, Robinson TL and Thomsen L: The search for the origin of rhythmicity in intestinal contraction; from tissue to single cells. Neurogastroenterol Motil 12: 3-9, 2000.

33. Jee SR, Morales W, Low K, Chang C, Zhu A, Pokkunuri V, Chatterjee S, Soffer E, Conklin JL and Pimentel M: ICC density predicts bacterial overgrowth in a rat model of post-infectious IBS. World J Gastroenterol 16: 3680-3686, 2010

34. Burns AJ, Herbert TM, Ward SM and Sanders KM: Interstitial cells of Cajal in the guinea-pig gastrointestinal tract as revealed by c-Kit immunohistochemistry. Cell Tissue Res 290: 11-20, 1997.

35. Blair PJ, Bayguinov Y, Sanders KM and Ward SM: Interstitial cells in the primate gastrointestinal tract. Cell Tissue Res 350 199-213, 2012.

36. Mitsui R and Komuro T: Distribution and ultrastructure of interstitial cells of Cajal in the gastric antrum of wild-type and Ws/Ws rats. Anat Embryol (Berl) 206: 453-460, 2003.

37. Miyamoto-Kikuta S, Ezaki T and Komuro T: Distribution and morphological characteristics of the interstitial cells of Cajal in the ileocaecal junction of the guinea-pig. Cell Tissue Res 338: 29-35, 2009.

38. Gao J, Du P, O'Grady G, Archer R, Gibbons SJ, Farrugia G and Cheng LK: Cellular automaton model for simulating tissue-specific intestinal electrophysiological activity. Conf Proc IEEE Eng Med Biol Soc 2013: 5537-5540, 2013.

39. Bassotti $\mathrm{G}$ and Villanacci V: Colonic diverticular disease: Abnormalities of neuromuscular function. Dig Dis 30: 24-28, 2012

40. Huang $X$ and $\mathrm{Xu}$ WX: The pacemaker functions of visceral interstitial cells of Cajal. Sheng Li Xue Bao 62: 387-397, 2010.

41. Shin DH, Lee MJ, Jiao HY, Choi S, Kim MW, Park CG, Na J, Kim SW, Park IK, So I and Jun JY: Regulatory roles of endogenous mitogen-activated protein kinases and tyrosine kinases in the pacemaker activity of colonic interstitial cells of cajal. Pharmacology 96: 16-24, 2015.

42. Sohn W, Lee OY, Lee SP, Lee KN, Jun DW, Lee HL, Yoon BC, Choi HS, Sim J and Jang KS: Mast cell number, substance P and vasoactive intestinal peptide in irritable bowel syndrome with diarrhea. Scand J Gastroenterol 49: 43-51, 2014.

43. Braak B, Klooker TK, Wouters MM, Welting O, van der Loos CM, Stanisor OI, van Diest S, van den Wijngaard RM and Boeckxstaens GE: Mucosal immune cell numbers and visceral sensitivity in patients with irritable bowel syndrome: Is there any relationship? Am J Gastroenterol 107: 715-726, 2012.

44. Tsang CM, Wong CK, Ip WK and Lam CW: Synergistic effect of SCF and TNF-alpha on the up-regulation of cell-surface expression of ICAM-1 on human leukemic mast cell line (HMC)-1 cells. J Leukoc Biol 78: 239-247, 2005.

45. Draber P, Halova I, Polakovicova I and Kawakami T: Signal transduction and chemotaxis in mast cells. Eur J Pharmacol 778: $11-23,2016$

46. Collmann E, Bohnacker T, Marone R, Dawson J, Rehberg M, Stringer R, Krombach F, Burkhart C, Hirsch E, Hollingworth GJ, et al: Transient targeting of phosphoinositide 3-kinase acts as a roadblock in mast cells' route to allergy. J Allergy Clin Immunol 132: 959-968, 2013.

47. Kojima T, Hirota Y, Ema M, Takahashi S, Miyoshi I, Okano H and Sawamoto K: Subventricular zone-derived neural progenitor cells migrate along a blood vessel scaffold toward the post-stroke striatum. Stem Cells 28: 545-554, 2010.

48. Jin K, Mao XO, Sun Y, Xie L and Greenberg DA: Stem cell factor stimulates neurogenesis in vitro and in vivo. J Clin Invest 110: 311-319, 2002.

49. Drăghici IM, Drăghici L, Cojocaru M, Gorgan CL and Vrabie CD: The immunoprofile of interstitial Cajal cells within adenomyosis/endometriosis lesions. Rom J Morphol Embryol 56: 133-138, 2015.

50. Lu T, Luo Y, Sun H, Qin W and Li Y: Electroacupuncture improves behavioral recovery and increases $\mathrm{SCF} / \mathrm{c}$-kit expression in a rat model of focal cerebral ischemia/reperfusion. Neurol Sci 34: 487-495, 2013

51. Micheva-Viteva SN, Shou Y, Nowak-Lovato KL, Rector KD and Hong-Geller E: c-KIT signaling is targeted by pathogenic Yersinia to suppress the host immune response. BMC Microbiol 13: 249, 2013.

52. Guo S, Tao X, Wang Y, Tang J, Shen L and Song C: SCF/c-Kit signaling promotes invasion of T24 cells via PI3K pathway. Nan Fang Yi Ke Da Xue Xue Bao 34: 507-510, 2014 (In Chinese). 
53. Zheng $\mathrm{Z}$ and Tang $\mathrm{H}$ : Decreased neuroplasticity may play a role in irritable bowel syndrome: Implication from the comorbidity of depression and irritable bowel syndrome. J Neurogastroenterol Motil 21: 298-299, 2015.

54. Da Silva CA, Reber L and Frossard N: Stem cell factor expression, mast cells and inflammation in asthma. Fundam Clin Pharmacol 20: 21-39, 2006.

55. Xiao Y: SCF/c-Kit signaling acts as a new etiologic factor of depression by regulation adult neurogenesis. $\mathrm{PhD}$ dissertation. Shanghai Jiaotong University, China, 2010.

56. Keightley P, Pavli P, Platten J and Looi JC: Gut feelings 1. Mind, mood and gut in irritable bowel syndrome: Approaches to psychiatric care. Australas Psychiatry 23: 403-406, 2015.

57. Muscatello MR, Bruno A, Scimeca G, Pandolfo G and Zoccali RA: Role of negative affects in pathophysiology and clinical expression of irritable bowel syndrome. World $\mathbf{J}$ Gastroenterol 20: 7570-7586, 2014.

58. Guo XZ: SCF/c-Kit signaling acts as a new etiological factor of depression by regulating adult hippocampal neurogenesis. In Proceedings of the Chinese society of genetic model organisms and human health conference, 2010.

59. Zhao X, Suo HY, Qian Y, Li GJ, Liu ZH and Li J: Therapeutic effects of Lactobacillus casei Qian treatment in activated carbon-induced constipated mice. Mol Med Rep 12: 3191-3199, 2015.

60. Matsumoto K, Hosoya T, Tashima K, Namiki T, Murayama T and Horie S: Distribution of transient receptor potential vanilloid 1 channel-expressing nerve fibers in mouse rectal and colonic enteric nervous system: Relationship to peptidergic and nitrergic neurons. Neuroscience 172: 518-534, 2011.

61. DiNitto JP, Deshmukh GD, Zhang Y, Jacques SL, Coli R, Worrall JW, Diehl W, English JM and Wu JC: Function of activation loop tyrosine phosphorylation in the mechanism of c-Kit auto-activation and its implication in sunitinib resistance. J Biochem 147: 601-609, 2010.

62. Yamamoto T, Watabe K, Nakahara M, Ogiyama H, Kiyohara T, Tsutsui S, Tamura S, Shinomura Y and Hayashi N: Disturbed gastrointestinal motility and decreased interstitial cells of Cajal in diabetic db/db mice. J Gastroenterol Hepatol 23: 660-667, 2008.

63. Okumura T: Brain-gut interaction in the pathophysiology of IBS. Nihon Shokakibyo Gakkai Zasshi 111: 1334-1344, 2014 (In Japanese).

64. Keszthelyi D, Troost FJ, Jonkers DM, van Eijk HM, Dekker J, Buurman WA and Masclee AA: Visceral hypersensitivity in irritable bowel syndrome: Evidence for involvement of serotonin metabolism-a preliminary study. Neurogastroenterol Motil 27: 1127-1137, 2015.

65. Sun J, Wu X, Meng Y, Cheng J, Ning H, Peng Y, Pei L and Zhang W: Electro-acupuncture decreases 5-HT, CGRP and increases NPY in the brain-gut axis in two rat models of Diarrhea-predominant irritable bowel syndrome(D-IBS). BMC Complement Altern Med 15: 340, 2015.
66. Camilleri M, Oduyebo I and Halawi H: Chemical and molecular factors in irritable bowel syndrome: Current knowledge, challenges, and unanswered questions. Am J Physiol Gastrointest Liver Physiol 311: G777-G784, 2016.

67. Murakami M, Austen KF and Arm JP: The immediate phase of c-kit ligand stimulation of mouse bone marrow-derived mast cells elicits rapid leukotriene $\mathrm{C} 4$ generation through posttranslational activation of cytosolic phospholipase A2 and 5-lipoxygenase. J Exp Med 182: 197-206, 1995.

68. Pynaert G, Grooten J, van Deventer SJ and Peppelenbosch MP: Cysteinyl leukotrienes mediate histamine hypersensitivity ex vivo by increasing histamine receptor numbers. Mol Med 5: 685-692, 1999.

69. Bloemers SM, Verheule S, Peppelenbosch MP, Smit MJ, Tertoolen LG and de Laat S: Sensitization of the histamine H1 receptor by increased ligand affinity. J Biol Chem 273: 2249-2255, 1998.

70. Martínez C, Lobo B, Pigrau M, Ramos L, González-Castro AM, Alonso C, Guilarte M, Guilá M, de Torres I, Azpiroz F, et al: Diarrhoea-predominant irritable bowel syndrome: An organic disorder with structural abnormalities in the jejunal epithelial barrier. GUT 62: 1160-1168, 2013.

71. Vicario M, González-Castro AM, Martinez C, Lobo B, Pigrau M, Guilarte M, de Torres I, Mosquera JL, Fortea M, Sevillano-Aguilera C, et al: Increased humoral immunity in the jejunum of diarrhoea-predominant irritable bowel syndrome associated with clinical manifestations. GUT 64: 1379-1388, 2015.

72. Willot S, Gauthier C, Patey N and Faure C: Nerve growth factor content is increased in the rectal mucosa of children with diarrhea-predominant irritable bowel syndrome. Neurogastroenterol Motil 24: 734-739, e347, 2012.

73. Eby JM, Kang HK, Klarquist J, Chatterjee S, Mosenson JA, Nishimura MI, Garrett-Mayer E, Longley BJ, Engelhard VH, Mehrotra S and Le Poole IC: Immune responses in a mouse model of vitiligo with spontaneous epidermal de- and repigmentation. Pigment Cell Melanoma Res 27: 1075-1085, 2014.

74. Zhang JY, Huang YX, Qin M and Wang JJ: Effect of overactivation of stem cell factor/c-kit on hyperalgesia in rats with irritable bowel syndrome. Journal of Shangxi Medical University 3: 177-181, 2012.

75. Siehl J and Thiel E: C-kit, GIST, and imatinib. Recent Results Cancer Res 176: 145-151, 2007.

76. D'Antonio C, Wang B, McKay C and Huizinga JD: Substance $\mathrm{P}$ activates a non-selective cation channel in murine pacemaker ICC. Neurogastroenterol Motil 21: e979-985, 2009.

77. Milenkovic N, Frahm C, Gassmann M, Griffel C, Erdmann B, Birchmeier C, Lewin GR and Garratt AN: Nociceptive tuning by stem cell factor/c-Kit signaling. Neuron 56: 893-906, 2007.

78. Chen J, Du L, Xiao YT and Cai W: Disruption of interstitial cells of Cajal networks after massive small bowel resection. World J Gastroenterol 19: 3415-3422, 2013. 